\title{
A rotavirose e a vacina oral de rotavírus humano no cenário brasileiro: revisão integrativa da literatura
}

\author{
The rotavirus disease and the oral human rotavirus vaccination \\ in the Brazilian scenario: an integrative literature review
}

Pétala Tuani Candido de Oliveira Salvador ${ }^{1}$

Taciana Jacinto de Almeida ${ }^{1}$

Kisna Yasmin Andrade Alves ${ }^{1}$

Cilene Nunes Dantas ${ }^{1}$

${ }^{1}$ Faculdade de Ciências, Cultura e Extensão do Rio Grande do Norte.

Rua Orlando Silva 2.897, Capim Macio. 59080-020 Natal RN

petalatuani@hotmail.com

\begin{abstract}
Due to the epidemiological relevance of rotavirus disease on the worldwide panorama as an important cause of morbid-mortality in the infantile public and to the still incipient production of studies concerning the problematic in the nationwide scenario, not to mention the unique necessity of encouraging the promotion of care and education as inseparable factors in the health spaces, it was delimited as study object of the present article the rotavirus disease in the Brazilian scenario, emphasizing the vaccination as preventive measure against this ill. Thus it is aimed to analyze the publications about rotavirus disease in our country's contexture, stressing the vaccination against the Rotavirus (VORH) as the strategy mentioned. It is a bibliographic research performed on the BDENF, Lilacs, SciELO and Medline databases, in February 2010. During the study the following thematic pillars were discussed: rotavirus characteristics; the rotavirus disease as a public health issue; and the vaccination against rotavirus as primordial action of health care. The study evidenced the epidemiological importance of rotavirus disease in the worldwide scenario and the relevance of vaccination as preventive measure against such problematics.
\end{abstract}

Key words Rotavirus, Rotavirus infections, Rotavirus vaccines
Resumo Diante da relevância epidemiológica da rotavirose no panorama mundial como importante causa de morbimortalidade no público infantil e da ainda incipiente produção de estudos que versem sobre a problemática no cenário nacional, sem falar na necessidade impar de se incentivar o fomento de fazeres educativos que conjuguem o cuidado e a educação como fatores indissociáveis nos espaços de saúde, foi delimitado como objeto de estudo do presente artigo a rotavirose no cenário brasileiro, destacando a vacinação como estratégia de combate a esse mal. Assim, objetivase analisar as publicações sobre rotavirose no contexto do nosso país, ressaltando a vacina contra rotavírus (VORH) como a mencionada estratégia. Trata-se de uma pesquisa bibliográfica realizada nos bancos de dados BDENF, Lilacs, SciELOe Medline, no mês de fevereiro de 2010. No decorrer do estudo, são discutidos os seguintes pilares temáticos: propriedades do rotavírus; a rotavirose como um problema de saúde pública; e a vacinação contra o rotavírus como ação primordial de proteção à saúde. O estudo evidenciou a importância epidemiológica da rotavirose no cenário mundial e a relevância da vacinação como estratégia de combate a tal problemática.

Palavras-chave Rotavírus, Infecções por rotavírus, Vacinas contra rotavírus 


\section{Introdução}

Ao longo dos anos, o Sistema Único de Saúde (SUS) vem se reestruturando para proporcionar um adequado atendimento à população brasileira, adquirindo experiências significativas nos setores da promoção, da proteção e da recuperação da saúde. Através de sua criação e consolidação pela Constituição Federal de 1988, tornouse premente para o Brasil viabilizar seus princípios e suas diretrizes, buscando assegurar qualidade e resolutividade no atendimento, bem como proteger os cidadãos das principais doenças existentes no país.

Para assegurar a qualidade dos serviços prestados pelo SUS, a Lei $\mathrm{n}^{\circ} 8.080$, de 19 de setembro de 1990, dispõe tanto sobre as condições para a assistência à saúde quanto sobre a organização e o funcionamento dos serviços de saúde e a responsabilidade das três esferas governamentais federal, estadual e municipal - de garantir atendimentos nas Unidades Básicas de Saúde, hospitais e residências da comunidade. Para tanto, dentre as suas várias atribuições podemos destacar a monitorizarão, a avaliação e a fiscalização das ações e serviços de saúde, o acompanhamento, a avaliação e a divulgação do nível de saúde da população, a organização e a coordenação dos sistemas de informações de saúde, objetivando a realização integrada das ações assistenciais e preventivas ${ }^{1}$.

Uma das metas importantes do SUS e, portanto, do Ministério da Saúde é a redução da morbidade e da mortalidade infantil, garantindo, para isso, o acesso aos serviços de saúde a toda a população, o que é reforçado pela Estratégia Saúde da Família (ESF), que teve seus aspectos norteadores definidos em 28 de março de 2006 por meio da Portaria no 648, que disponibiliza a assistência a todas as crianças pela Equipe Multiprofissional da ESF. Durante as consultas, é ressaltada a importância de se solidificar a alimentação adequada para a idade, medidas de higiene, calendário de vacinação atualizado e o desenvolvimento psicomotor e intelectual da criança, o que pode ser realizado durante as consultas de crescimento e desenvolvimento (C e D), em crianças de 0 a 6 anos de idade 2 .

O diagnóstico no Brasil sobre a mortalidade infantil denota declínio desta. A configuração atual é de que o país está entre os 16 países, em um grupo de 68, a alcançar a quarta meta dos Objetivos de Desenvolvimento do Milênio em 2012, fixado pela Organização das Nações Unidas (ONU), qual seja, a taxa de 14,4 mortes por mil nascidos vivos. Esse decréscimo é resultante da conjugação de vários fatores: aumento da cobertura vacinal da população e durante o prénatal, aumento da ampliação dos serviços de saúde, do uso da terapia de reidratação oral, do grau de escolaridade da população e das taxas de aleitamento materno ${ }^{3}$.

Diante dessa magnitude, é necessário pôr-se em relevo o grande avanço no sistema de vacinação nacional, o que configura o Brasil como um dos primeiros países do mundo a adotar um calendário de vacinação. Nesse contexto, é essencial realçar a diferença fundamental entre vacinação e imunização. Enquanto a primeira consiste no ato técnico de aplicar um imunobiológico, a segunda envolve um contexto mais amplo, uma vez que imunizar significa tornar não suscetível a uma determinada doença e, dessa forma, preveni-la ${ }^{4}$. Assim, para que a imunização de fato ocorra, o ato de vacinar deve ser permeado por aspectos técnicos essenciais, norteados por uma rede de frios adequada e eficaz, tanto do ponto de vista de recursos materiais quanto de recursos humanos qualificados. Diante desse panorama, destaca-se que um dos escopos do Programa Nacional de Imunizações (PNI) é garantir a excelência de qualidade dos imunobiológicos a serem aplicados, ou seja, não garantir tão somente a vacinação, mas uma perfeita e adequada imunização ${ }^{5}$.

O Programa Nacional de Imunizações (PNI) foi instituído em 1973, objetivando o controle das doenças imunopreveníveis através de coberturas vacinais da população, promovendo uma adequada proteção imunitária contra determinadas doenças abrangentes no programa ${ }^{5,6}$.

Mesmo com o declínio da mortalidade infantil supracitado e do avanço do PNI, é válido registrar que ainda existe uma subnotificação dos óbitos no país, o que se configura como um problema maior nas regiões Norte e Nordeste. Essa problemática compromete a identificação dos fatores determinantes para tal evento, acarretando sérios problemas e entraves para as ações de prevenção e assistência à saúde . $^{7}$.

Vale salientar que o problema das subnotificações está amplamente relacionado à falta de orientação dos familiares e ao não preenchimento de campos relevantes nas certidões de óbitos, o que ocasiona problemas nas ações e investimentos quanto à melhoria da assistência para detecção de novos casos de doenças, as quais poderão levar a novos óbitos.

Para tanto, cumpre ressaltar a importância do PNI e a consolidação do calendário de vacinação de todas as crianças no âmbito nacional, o que constitui um fator determinante para a diminuição de doenças e óbitos no Brasil. 
As vacinas encontram-se no conjunto dos mecanismos de proteção imunológica em que o organismo reconhece uma substância como estranha para metabolizá-la ou neutralizá-la. Essa resposta imune depende basicamente dos fatores inerentes ao organismo ou às vacinas ${ }^{5}$.

O PNI oferta vários tipos de imunobiológicos, tanto para crianças como para adultos, sendo que a mais nova vacina do calendário para menores de um ano de idade é a vacina oral contra o rotavírus humano (VORH), objeto de estudo deste trabalho.

Os investimentos em pesquisas para disponibilizar uma vacina eficaz e segura contra o rotavírus vêm sendo realizados desde $1980^{8}$, quando já se reconhecia a importância epidemiológica desse patógeno para os altos índices de morbidade e mortalidade infantil, por diarreia, dele decorrente. A primeira vacina contra rotavírus foi licenciada nos EUA em 1998, a qual, menos de um ano depois, teve sua comercialização suspensa em decorrência do aumento na notificação de casos de intussuscepção em crianças vacinadas ${ }^{9}$. Tal fato deu gênese a várias discussões entre os pesquisadores, que buscavam uma solução eficaz que pudesse responder à importância que o agravo assumia em nível mundial.

No Brasil, os estudos começaram a ser desenvolvidos no início da década de 90 . Nesse período, os estudiosos avaliaram a inocuidade, a imunogenicidade e a eficácia de três doses de uma vacina tetravalente capaz de prevenir a diarreia causada pelo vírus da família Reoviridae, a rotavirose ${ }^{10}$. Em março de 2006, o Brasil introduziu no Calendário Vacinal Infantil a vacina contra rotavírus, o que representou um grande avanço nas ações de proteção à saúde do país. A vacina oral de rotavírus humano (VORH) foi licenciada pela Agência Nacional de Vigilância Sanitária (Anvisa) em junho de 2005, com o nome comercial de Rotarix ${ }^{10-12}$.

Diante dessa perspectiva e tendo em vista não só a relevância epidemiológica da rotavirose no panorama mundial mas também a ainda incipiente produção de estudos que versem sobre a problemática no cenário nacional, isso sem falar na necessidade ímpar de se incentivar o fomento de fazeres educativos que conjuguem o cuidado e a educação como fatores indissociáveis nos espaços de saúde - compreendendo que "para que possamos reduzir a taxa de morbimortalidade das doenças imunopreveníveis torna-se importante conhecermos a situação desses agravos"2 (p. 27) -, foi delimitado como objeto de estudo do presente artigo a rotavirose no cenário brasileiro, destacando a vacinação como estratégia de combate a tal problemática de saúde.

\section{Objetivo e métodos}

O objetivo deste artigo é analisar as publicações sobre rotavirose no cenário brasileiro, destacando a vacina contra rotavírus (VORH) como estratégia de combate a tal problemática.

A pesquisa bibliográfica consiste naquela que é "desenvolvida a partir de material já elaborado, constituído principalmente de livros e artigos ci$e^{e n t i ́ f i c o s}{ }^{13}$ (p. 59). Seu objetivo é "revisar a literatura existente e não repetir o tema de estudo ou experimentação"13 (p. 58). Além disto, destaca que as informações secundárias são provenientes de documentos impressos em revistas, livros e dados estatísticos, entre outras fontes.

É válido realçar que o levantamento bibliográfico foi realizado nos bancos de dados BDENF (Banco de Dados em Enfermagem), Lilacs (Sistema Latino-Americano e do Caribe de Informação em Ciências da Saúde), SciELO (Scientific Electronic Library Online) e Medline (Medical Literature Analysis and Retrieval System Online), no mês de fevereiro de 2010. Essa revisão literária visou buscar os estudos realizados contemporaneamente que versavam sobre o rotavírus, a rotavirose e a vacina contra tal patógeno. Para a localização dos estudos, foram utilizados os seguintes descritores: rotavírus, infecções por rotavírus e vacinas contra rotavírus.

\section{Resultados e discussão}

Para a consolidação dos resultados deste estudo, foram realizadas atividades analíticas em artigos e informes técnicos do Ministério da Saúde e da Sociedade Brasileira de Imunizações, bem como nos dados disponíveis no DataSUS e na Sala de Situação do Ministério da Saúde.

Foram reveladas à equipe de pesquisadores, durante o desenvolver do percurso analítico das literaturas, a importância epidemiológica da rotavirose no cenário mundial e a relevância da vacinação como estratégia de combate a tal problemática. Desse modo, as produções estudadas proporcionaram tecer considerações e apresentações de resultados, as quais foram agrupadas nos seguintes pilares temáticos, discutidos a seguir: propriedades do rotavírus; a rotavirose como um problema de saúde pública; e a vacinação contra o rotavírus.

\section{Rotavírus: propriedades do patógeno}

Os rotavírus são membros da família Reoviridae e apresentam uma morfologia esférica com 
simetria icosaédrica, cerca de $100 \mathrm{~mm}$ de diâmetro e cápside viral constituído por três camadas proteicas concêntricas ${ }^{14}$. O genoma desse patógeno consiste em RNA de fita dupla com $11 \mathrm{seg-}$ mentos localizados dentro do nucleocapsídeo e com proteínas não estruturais, responsáveis por funções essenciais à replicação, patogênese e determinação da especificidade da espécie ${ }^{8}$.

Atualmente, são reconhecidos sete diferentes grupos de rotavírus, designados de $\mathrm{A}$ a $\mathrm{G}^{10}$. Os dos grupos A, B e C infectam o homem, enquanto os demais (D-G) não têm sido associados à patologia humana ${ }^{9}$. De maneira geral, os grupos sorológicos do rotavírus de importância epidemiológica para a espécie humana apresentam as seguintes características: o Grupo A, que abrange dois subgrupos com, pelo menos, 14 sorotipos diferentes, destaca-se como o de maior importância epidemiológica ${ }^{10,15}$; o Grupo B causou, apenas na China, grandes focos de gastrenterite em crianças e adultos; e o Grupo C, mesmo de distribuição mundial, só foi encontrado em baixa prevalência ${ }^{15}$.

Nessa perspectiva, os rotavírus que causam mais de 95\% das infecções em seres humanos correspondem aos do grupo A. Dentre os desse grupo, identificam-se diferentes tipos de antígenos (denominados "sorotipos") ${ }^{8}$. Os antígenos que determinam o sorotipo estão localizados em duas proteínas do cápside externo dos rotavírus: a glicoproteína VP7 e a proteína VP4 $4^{14}$. Na atualidade, foram descritos 14 tipos antigênicos VP7 humanos (denominados também de "tipos G", por se tratar de uma glicoproteína) e nove tipos antigênicos P (denominados "P", devido à "sensibilidade à protease") ${ }^{8}$. Destes, os mais frequentemente encontrados em todo o mundo são os sorotipos G1 a G4 ${ }^{11}$. Dados de Argentina, Brasil, Chile, Costa Rica, Equador, Honduras, México, Panamá e Venezuela estimam que mais da metade das hospitalizações por rotavírus se deve ao sorotipo $\mathrm{G} 1^{16}$.

Quando o ser humano ingere o vírus, a proteína VP4 da superfície externa dos rotavírus é fracionada, pelas enzimas pancreatina, tripsina ou elastase, em duas proteínas menores (VP5 e VP8), e após esse fenômeno o vírus adere às células do epitélio intestinal ${ }^{9}$. Assim, o principal sítio de replicação viral é o intestino delgado, em particular o jejuno, nas células do topo das vilosidades intestinais ${ }^{14}$. A lesão de tal epitélio desencadeia então o fenômeno de má absorção, devido, principalmente, à depressão transitória no nível das dissacaridases, resultando, por conseguinte, no caráter osmótico da diarreia ${ }^{11}$.

Diante dessa patogênese, o rotavírus é considerado, mundialmente, o mais importante agente etiológico de diarreia grave na infância, o que suscita a necessidade de compreendermos as particularidades da rotavirose como um problema de saúde pública.

\section{Rotavirose: um problema de saúde pública}

A rotavirose é uma síndrome caracterizada pelo aumento do número de evacuações, com fezes aquosas ou de pouca consistência, com frequência acompanhada de vômito, febre e dor abdominal, com duração de dois a 14 dias, sendo assim autolimitada e podendo apresentar-se das formas leves até as graves ${ }^{11}$.

A literatura é unânime em afirmar que a infecção por rotavirus constitui-se na principal causa de diarreia grave em crianças, contribuindo para uma elevada morbidade hospitalar e mortalidade. Globalmente, o rotavírus é o responsável, a cada ano, por 114 milhões de episódios de gastrenterite, 24 milhões de consultas, 2,4 milhões de hospitalizações em menores de cinco anos e 611 mil mortes infantis $(80 \%$ nos países pobres), o que representa a cifra de $5 \%$ da mortalidade infantil mundial ${ }^{17}$.

Diante desses dados alarmantes, a rotavirose constitui a segunda causa de morte mundial nos menores de cinco anos, sendo precedida apenas pelas infecções respiratórias ${ }^{16}$. Segundo registros, morrem a cada dia 2.000 crianças com quadro diarreico causado por esse patógeno ${ }^{18}$.

Nessa conjuntura, estima-se que, ao completar 5 anos, uma criança terá sido afetada por pelo menos um episódio de gastroenterite por rotavírus; uma de cada cinco crianças terá visitado uma unidade de saúde; e uma de cada 65 terá sido hospitalizada por essa causa ${ }^{16}$.

No Brasil, a realidade não difere da mundial. Dados do DataSUS referentes ao ano de 2006 revelam que ocorreram nesse período 2.236 óbitos por doenças diarreicas em menores de 5 anos. Esse contingente, por região de procedência, totalizou: 1.291 óbitos na região Nordeste; 363 na região Norte; 348 na Sudeste; 143 na Centro-Oeste; e 91 na região Sul. O estado com a maior cifra foi a Bahia, onde ocorreram 271 óbitos por doença diarreica nessa faixa etária, e o de menor número de casos de óbito foi o Amapá, com apenas três mortes.

Dados de 2008 disponíveis na Sala de Situação do Ministério da Saúde revelam que, nesse ano, ocorreram 47.223 óbitos por doenças infecciosas e parasitárias na população brasileira. Desse total, 3.737 decorreram de diarreia e gastroenterite de origem infecciosa presumida e 1.128 , de diarreia em menores de 5 anos, o que representa uma tendência decrescente em relação ao ano de 2006. 
Tomando por base a estimativa de que $40 \%$ dos óbitos por doença diarreica em menores de cinco anos são devidos aos rotavírus ${ }^{12}$, é possível pressupor a média de óbitos por doença diarreica por rotavirus, em 2008, nessa mesma faixa etária, em 451 - o que ainda representa um dado alarmante, que necessita de estratégias eficazes de combate pelos três níveis federativos, envolvendo medidas resolutivas de atenção e assistência à saúde dos usuários do Sistema Único de Saúde brasileiro.

Em países desenvolvidos, assim como no Brasil, a importância da rotavirose deve-se, dentre outros fatores, aos seus danos à saúde, afetando o desenvolvimento infantil, aos custos gerados pela demanda por serviços médicos e às perdas de dias de trabalho e de escola, gastos com medicamentos, transportes etc. ${ }^{19}$. Em suma, trata-se de um agravo de grandes repercussões. Para se fazer frente a tal problemática de consequências alarmantes para a população brasileira e mundial, torna-se imperativo conhecer as particularidades desse mal.

A rotavirose pode ocorrer em qualquer idade, embora as doenças sintomáticas predominem na faixa etária de 6 a 24 meses $^{9}$. Em geral, as crianças se infectam nos primeiros anos de vida, sendo que os casos mais graves ocorrem principalmente até os dois anos de idade ${ }^{10}$.

Dentre os mecanismos de transmissão do rotavírus, destaca-se a via fecal-oral $1^{8,10,15,19-21}$. Estima-se que as fezes de crianças infectadas apresentam altas concentrações desse patógeno, excretados dois dias antes do início dos sinais e sintomas e até 21 dias após esse período ${ }^{8}$. Pessoas infectadas por rotavírus excretam até um trilhão de partículas em um ml de fezes, e como a carga viral necessária para infectar o homem é muito baixa (dez partículas), as epidemias são muito comuns ${ }^{9}$.

Outras formas de transmissão citadas na literatura são: brinquedos e superfícies de ambientes como pré-escolas e escolas ${ }^{8}$; água, alimentos e objetos contaminados; e secreções respiratórias ${ }^{10,19}$. Além disso, estudos trazem o rotavírus como uma importante causa de diarreia nosocomial ${ }^{15}$. Portanto, vê-se que esse patógeno possui eficientes mecanismos de exposição universal, os quais ignoram diferenças culturais regionais e nacionais ${ }^{20}$.

O quadro clínico típico da rotavirose é diarreia e vômito acompanhados de febre, náusea, anorexia, cãibras e mal-estar, que podem ser leves ou gerar complicações ${ }^{20}$. A febre precede o início da diarreia em 30 a 50\% das crianças; os vômitos ocorrem em mais de $80 \%$ das infecções; as fezes são aquosas, isotônicas e raramente con- têm muco, sangue ou leucócitos em número elevado $^{21}$. Nos casos graves, pode haver desidratação e acidose ${ }^{15}$. A duração do quadro clínico é, em média, de quatro a cinco dias, embora o período possa variar de um a dez ou mais dias ${ }^{8}$.

O tratamento da rotavirose é apenas de suporte e alicerça-se na hidratação, primeiramente por via oral, e na ocorrência de vômitos e diarreias graves, por via endovenosa, o que requer internação $0^{8,15,21}$. O uso de antimicrobianos e de antidiarreico não é recomendado ${ }^{11}$.

Quanto à sazonalidade do rotavírus no território nacional, esta se apresenta de forma variável: ocorre um aumento na incidência do patógeno nos meses mais frios ou no período de seca, entre maio e setembro, nos estados das regiões central e Sudeste; no Norte e no Nordeste, a ocorrência de rotavírus se distribui por todo o ano ${ }^{19}$.

Diante da importância epidemiológica desse patógeno no panorama mundial, a Organização Mundial da Saúde considera a vacinação como uma das intervenções de saúde pública capaz de gerar o maior impacto na prevenção de doenças infectocontagiosas, à semelhança do que ocorre com o consumo de água potável ${ }^{8}$. Dentre os motivos de se vir a consolidar a imunização contra o rotavírus, destacam-se: a ocorrência universal da infecção, sem grandes distinções entre os países desenvolvidos e em desenvolvimento; a capacidade parcial e incipiente da higiene ambiental no controle da rotavirose; a inexistência de um tratamento antiviral efetivo; o fato de a maior mortalidade por diarreia decorrente de o rotavírus ocorrer em comunidades pobres; e por ser esta uma enfermidade de alto impacto familiar, social e econômico ${ }^{15}$.

Nesse sentido, é imprescindível conhecer as particularidades da VORH utilizada no contexto brasileiro, bem como investigar a cobertura vacinal atual do Brasil, a fim de poder elucidar os avanços e desafios que caracterizam contemporaneamente essa problemática.

\section{Vacina oral de rotavírus humano (VORH): a estratégia de combate à rotavirose}

A literatura, em unanimidade, aponta a vacinação como a mais relevante estratégia de combate à rotavirose. Nesse sentido, a nação brasileira consolidou um grande avanço em 2006, ao incluir a VORH em seu calendário básico de vacinação, isso porque, conforme supracitado, tal medida de proteção à saúde é reconhecida como a única capaz de diminuir significativamente a incidência dos episódios severos ocasionados pelo rotavírus ${ }^{22}$. 
Estimativas mundiais calculam que, nas nações da América Latina, a vacinação efetiva contra esse patógeno será capaz de abater a mortalidade por rotavirose em $60 \%$ ou mais ${ }^{17}$. Atualmente, as cifras brasileiras acerca da eficácia da VORH utilizada no país revelam que a proteção para todas as diarreias por rotavírus é de aproximadamente 70\%; para as formas graves, é de $86 \%$ a $98 \%$; e, para hospitalização por diarreia por rotavírus, é de $80 \%$ a $95 \%{ }^{4}$. Dessa forma, é inquestionável a necessidade de se solidificar, na prática profissional, a eficiência de tal vacina, garantindo que os recursos materiais e humanos envolvidos na vacinação efetuem de forma resolutiva a imunização dos usuários menores de 2 anos, o que influirá diretamente nos indicadores de morbimortalidade do rotavírus.

No momento atual, existem duas vacinas contra o rotavírus aprovadas no Brasil: uma vacina monovalente, sorotipo G1P[8], que está disponível na rede pública; e uma vacina pentavalente, composta pelos seguintes sorotipos: G1P[5], G2P[5], G3P[5], G4P[5] e G6P[8] ${ }^{4}$.

Assim, a vacina que integra o calendário básico de vacinação atual do Sistema Único de Saúde brasileiro é a denominada de "vacina oral de rotavírus humano (VORH)", a qual, no mercado internacional, foi licenciada com o nome comercial de "Rotarix"11.

A VORH é composta de vírus isolados de seres humanos e atenuados, que permitem a manutenção de sua capacidade imunogênica, porém não patogênica. A apresentação é em monodose, sendo que cada dose da VORH contém: frasco com pó liofilizado e aplicador com diluente; após a reconstituição, cada dose corresponde a $1 \mathrm{ml}$, a qual deve ser administrada exclusivamente por via oral $^{10,11}$. O imunobiológico deve ser mantido a uma temperatura entre $+2^{\circ} \mathrm{C} \mathrm{e}+8^{\circ} \mathrm{C}$, seguindo, portanto, as normas técnicas de rede de frio do $\mathrm{PNI}^{4,11}$.

O esquema vacinal adotado depende do tipo da vacina. Para aquela utilizada pelo Ministério da Saúde - a monovalente -, o esquema é composto por duas doses, a serem administradas aos 2 e 4 meses de idade. Convém ressaltar que existem orientações precisas quanto à faixa etária de aplicação das doses vacinais que devem ser rigorosamente respeitadas: para a administração da primeira dose, a idade mínima é de 1 mês e meio, e a máxima, de 3 meses e 7 dias; e para a segunda dose, a idade mínima é de 3 meses e 7 dias e a máxima, de 5 meses e meio ${ }^{4,10,11}$. A proteção tem início cerca de duas semanas após a segunda dose ${ }^{10}$.

A eficácia de tal esquema vacinal é comprovada pelos pesquisadores. Estudos revelam que o esquema com duas doses de vacina foi considerado imunogênico em lactentes previamente soronegativos, havendo, inclusive, uma grande tendência de soroconversão com concentrações virais elevadas. A segunda dose da vacina, por sua vez, aumentou significativamente as taxas de soropositividade ${ }^{23}$.

É válido realçar que a vacinação que descumprir as faixas etárias preconizadas deverá ser considerada um procedimento inadequado, sendo que as crianças submetidas a tal evento deverão ser consideradas crianças vacinadas inadvertidamente que precisam ser acompanhadas, por um período de 30 dias, em quatro visitas semanais ${ }^{11}$.

Dentre os cuidados que devem constar na vacinação contra rotavírus, destacam-se: antes do procedimento, não há restrições quanto ao consumo de líquidos ou alimentos, inclusive leite materno; ao aplicar o imunobiológico, seguir as normas técnicas estabelecidas pelo PNI e não repetir a dose caso a criança vomite ou regurgite; e, após o procedimento, orientar quanto à manutenção de uma higiene pessoal adequada ao se manusear as fezes das crianças vacinadas, tendo em vista a eliminação de vírus vacinal por esse meio, sendo que a lavagem das mãos deve ser enfatizada como a forma mais eficaz de manter tal cuidado, especialmente após manuseio de fraldas ${ }^{10,11}$.

A VORH deverá ser adiada nos seguintes casos: na presença de doenças agudas febris graves ou de diarreia que necessita de hospitalização ${ }^{10}$. Já a contraindicação deverá ser concretizada na iminência das seguintes situações: imunodeficiência congênita ou adquirida; uso de corticosteroides em doses imunossupressoras; uso de imunossupressores; presença de doença gastrointestinal crônica; malformação congênita do trato digestivo; história prévia de intussuscepção; ou nos casos de histórico de reação alérgica grave a um dos componentes da vacina, em dose anterior até duas horas após a aplicação desta ${ }^{4,10,11}$.

A vacina para rotavírus pode ser aplicada simultaneamente com as outras vacinas do calendário, exceto com a vacina antimeningocócica conjugada tipo $\mathrm{C}$, para a qual não há experiência suficiente para uma recomendação ${ }^{4}$. No caso da pólio oral, se não for utilizada no mesmo dia, deve-se respeitar intervalo de 15 dias $^{4,10,11}$.

Diante disso, o Ministério da Saúde estabeleceu o indicador de cobertura vacinal para a VORH em $90 \%{ }^{11}$. Os dados trazidos pela Sala de Situação do MS revelam que, em 2009, da população menor de um ano, que totalizava 6.380.189 crianças, a vacina contra o rotavírus foi devidamente aplicada em 5.238.685 infantes, o que traduz uma cobertura vacinal de $82 \%$.

Destarte, vê-se que o desafio de garantir uma cobertura vacinal de $100 \%$ para a população in- 
fantil ainda está em vigência e requer de todos os envolvidos nesse processo um empenho intersetorial para concretizá-lo. Com isso, o avanço conquistado pelo Mistério da Saúde, por meio do PNI, poderá gerar, de forma integral e resolutiva, benefícios para a população brasileira, possibilitando que os princípios e diretrizes do Sistema Único de Saúde sejam efetivamente solidificados, contribuindo, assim, para a melhoria da qualidade de vida populacional.

\section{Considerações finais}

Diante das exposições realizadas, evidencia-se a relevância da infecção por rotavírus no cenário brasileiro do processo saúde/doença infantil, sendo esse patógeno o responsável principal pelos casos de diarreia grave e desidratação, acometendo especialmente crianças menores de cinco anos. Essa problemática exige da equipe multiprofissional o fomento de um novo olhar atento e qualificado sobre a temática.

Atualmente, destacam-se as ações de proteção da saúde mediante a imunização. Desde 2006, o Brasil tem uma importante ferramenta na prevenção e no controle das infecções pelo rotavírus: a vacina contra rotavírus (VORH), que foi inserida no calendário vacinal infantil. A adoção dessa medida foi fundamental para as mudanças no quadro epidemiológico brasileiro já explicitado.

No entanto, a compreensão e a adoção de ações de proteção da saúde fazem-se necessárias. A princípio, os profissionais das Unidades Básicas de Saúde/Unidades de Saúde da Família devem ser sensibilizados da importância, nos âmbitos local e nacional, das práticas de imunização. Essa peculiaridade traz à tona a capacitação dos profissionais que realizam seu trabalho na sala da vacina, abarcando saberes referentes à organização dos materiais e equipamentos da sala, uso dos instrumentos e impressos que devem estar presentes nesses ambientes, manuseio e acondici- onamento dos imunobiológicos conforme a normatização dos manuais expedidos pelo Ministério da Saúde, bem como de outros órgãos competentes. A educação em saúde possibilitará, assim, a eficácia das práticas de imunização com vistas ao seguimento coerente de suas etapas.

Nessa perspectiva, vale enfatizar a importância tripartite do poder público. É fundamental que as esferas desse poder forneçam recursos humanos e materiais adequados e compatíveis com a realização de um processo de trabalho em saúde satisfatório, resolutivo e de direito dos cidadãos.

Quanto à educação em saúde, é notória a essencialidade da realização de atividades que representem um alicerce na construção de saberes e adequação de hábitos de vida da comunidade. Sabe-se que, em sua grande maioria, a falta de esclarecimentos acerca da vacinação e o medo que essa ação de saúde faz emergir nos usuários com baixo nível de escolaridade constituem, dentre outros, empecilhos para se desenvolver uma boa cobertura vacinal. Desse modo, é imperativo o papel do profissional de saúde no diálogo com esses usuários. Além do mais, é esse profissional o sujeito responsável por consolidar os vínculos comunidade-unidade de saúde.

Assim, com a conjugação desses pressupostos, torna-se possível a concretização satisfatória das atividades de proteção da saúde supracitada, chegando-se, inclusive, por meio desse processo, a reduzir as taxas de morbidade e mortalidade decorrentes da infecção por rotavírus.

Este trabalho tenciona constituir-se numa ferramenta de sensibilização de competência e responsabilidade para as categorias acadêmica e profissional, buscando conscientizá-las da criação necessária de estratégias que abarquem o processo de imunização, destacando como passo inicial a construção de saberes. A busca por saberes foi apreciada e efetuada pelos discentes de enfermagem, a fim de que pudessem ser tecidas as informações presentes neste consolidado científico, o qual contribui inteiramente para a nossa formação.

\section{Colaboradores}

PTCO Salvador trabalhou na concepção, na pesquisa, nos resultados e na redação final; TJ Almeida trabalhou na concepção, na pesquisa, na introdução e na redação final; KYA Alves trabalhou na concepção, na pesquisa, nas considerações e na redação final; CN Dantas trabalhou na concepção, nos objetivos, na metodologia, na discussão e análise dos dados e na redação final. 


\section{Referências}

1. Brasil. Ministério da Saúde. Lei n 8.080, de 19 de setembro de 1980. [acessado 2010 mar 6]. Disponível em: http://www.planalto.gov.br/ccivil_03/leis/ 18080.htm

2. Brasil. Ministério da Saúde. Agenda de compromissos para a saúde integral da criança e redução da mortalidade infantil. Brasília: Ministério da Saúde; 2004. (Série A. Normas e Manuais Técnicos).

3. Brasil. Ministério da Saúde. Redução da mortalidade. [documento na Internet] [acessado 2010 mar 6]. Disponível em: http://189.28.128.100/portal/saude/ profissional/visualizar_texto.cfm?idtxt $=32203 \&$ janela $=1$

4. Gilio AE, coordenador. Manual de imunizações: Centro de Imunizações Hospital Israelita Albert Einstein. 4a ed. Rio de Janeiro: Elsevier; 2009.

5. Brasil. Ministério da Saúde. Manual de normas de vacinação. $3^{a}$ ed. Brasília: Fundação Nacional de Saúde, Ministério da Saúde; 2001.

6. Castilho NM, Leuzzi C, Pontes SMF, Leuzzi MT. Saúde Coletiva. In: Murta GF, organizador. Saberes e práticas: guia para ensino e aprendizado de enfermagem. 3a ed. São Caetano do Sul, SP: Difusão Editora; 2007. (Série Curso de Enfermagem).

7. Brasil. Ministério da Saúde. Manual de Vigilância do Óbito Infantil e Fetal e do Comitê do Óbito Infantil e Fetal. Brasília: Ministério da Saúde; 2009. (Série A. Normas e Manuais Técnicos).

8. Sociedade Brasileira de Imunizações. Informe Rotavírus 2006 [periódico na Internet] 2006 [cerca de 4p.]. [acessado 2010 fev 20]. Disponível em: http:/ /sbim.org.br/sbim_info_rotavirus.pdf

9. Bricks LF. Rotavírus: atualização sobre doenças e vacinas. Pediatria (São Paulo) [periódico na Internet] 2005 [acessado 2010 feb 20]; 27(4): [p.8]. Disponível em: http://www.pediatriasaopaulo.usp.br/ upload/pdf/1146.pdf

10. Vranjac A. Vacina contra rotavírus. Rev Saúde Pública [periódico na Internet] 2006 [acessado 2010 feb 20]; 40(2). Disponível em: http://www.scielo.br/ $\mathrm{pdf} / \mathrm{rsp} / \mathrm{v} 40 \mathrm{n} 2 / 28545 . \mathrm{pdf}$

11. Brasil. Ministério da Saúde. Secretaria de Vigilância em Saúde. Departamento de Vigilância Epidemiológica. Informe Técnico - Doença Diarréica por Rotavírus: Vigilância Epidemiológica e Prevenção pela Vacina Oral de Rotavírus Humano - VORH, 2006. [Documento na Internet]. [acessado $2010 \mathrm{fev} 20$ ]. Disponível em: http://portal.saude.gov.br/portal/ arquivos/pdf/informe_rotavirus_02_03_2006.pdf

12. Carmo EH. Doença diarréica por rotavirus: magnitude, introdução da vacina e desafios para a vigilância epidemiológica. Cad Saude Publica [periódico na Internet] 2006 [acessado 2010 feb 20]; 22(11): [p.6.]. Disponível em: http://www.scielo.br/pdf/csp/ v22n11/01.pdf

13. Gonçalves HA. Manual de metodologia da pesquisa científica. São Paulo: Avercamp; 2005.

14. Rácz ML, Munford V, Castilho JG, Resque HR. Gastroenterites virais. In: Trabulsi LR, Alterthum F, editores. Microbiologia. $4^{\text {a }}$ ed. São Paulo: Atheneu; 2005.
15. Comité Nacional de Infectología. Gastroenteritis por rotavirus y su prevención. Arch Argent Pediatr [periódico na Internet] 2006 [acessado $2010 \mathrm{fev} 20$ ]; 104(6) [p.6]. Disponível em: http://www.sap.org.ar/ docs/profesionales/consensos/v104n6a12.pdf

16. Nieto Guevara J, López O, González G. Impacto de la introducción de la vacuna contra el rotavirus en la hospitalización por gastroenteritis aguda grave en el Hospital del Niño de la Ciudad de Panamá. Rev Panam Salud Publica [periódico na Internet] 2008 [acessado 2010 feb 20]; 24(3): [p.6]. Disponível em: http:// www.scielosp.org/pdf/rpsp/v24n3/a05v24n3.pdf

17. Esparza-Aguilar M, Bautista-Márquez A, González-Andrade MC, Richardson-López-Collada VL. Mortalidad por enfermedad diarreica en menores, antes y después de la introducción de la vacuna contra el rotavirus. Salud Publica Mex [periódico na Internet] 2009 [acessado $2010 \mathrm{fev} 20$ ]; 51(4): [p.6]. Disponível em: http://bvs.insp.mx/rsp/_files/File/ 2009/Julio\%20Agosto/2-mortalidad.pdf

18. Linhares AC. Epidemiologia das infecções por rotavírus no Brasil e os desafios para o seu controle. Cad Saude Publica [periódico na Internet] 2000 [acessado 2010 fev 20]; 16(3): [p.10]. Disponível em: http://www.scielo.br/pdf/csp/v16n3/2949.pdf

19. Carmo EH. Diarréia e rotavírus. Rev Saúde Pública [periódico na Internet] 2004 [acessado $2010 \mathrm{fev}$ 20]; 38(6): [p.6]. Disponível em: http://www.scielo.br/ $\mathrm{pdf} / \mathrm{rsp} / \mathrm{v} 38 \mathrm{n} 6 / 14 . \mathrm{pdf}$

20. Bernstein DI. RIX4414 (Rotarix ${ }^{\mathrm{TM}}$ ): uma vacina contra o rotavírus humano com vírus vivo atenuado. $J$ Pediatr (Rio J) [periódico na Internet] 2007 [acessado 2010 fev 20]; 83(3): [p.6]. Disponível em: http:/ /www.scielo.br/pdf/jped/v83n3/v83n3a02.pdf

21. Bricks LF. Rotavírus: atualização sobre doenças e vacinas. Pediatria (São Paulo) [periódico na Internet] 2005 [acessado $2010 \mathrm{fev} 20$ ]; 27(4): [p.6]. Disponível em: http://www.pediatriasaopaulo.usp.br/ upload/pdf/1146.pdf

22. González R, Salas-Maronsky H, Balebona E, Martínez JR, Serrano N, Pérez-Schael I. Estudio epidemiológico y clínico de las diarreas por rotavirus en niños menores de 5 años atendidos en centros asistenciales del estado Miranda-Venezuela. Invest Clin [periódico na Internet] 2008 [acessado $2010 \mathrm{fev} 20$ ]; 49(4): [p.6]. Disponível em: http://www.scielo. org.ve/pdf/ic/v49n4/art05.pdf

23. Araujo EC, Clemens SAC, Oliveira CS, Justino MCA, Rubio P, Gabbay YB, Silva VB, Mascarenhas JDP, Noronha VL, Clemens R, Gusmão RHP, Sanchez N, Monteiro TAF, Linhares AC. RIX4414 Segurança, imunogenicidade e eficácia protetora de duas doses da vacina RIX4414 contendo rotavírus atenuado de origem humana. J Pediatr (Rio J) [periódico na Internet] 2007 [acessado $2010 \mathrm{fev} 20$ ]; 83(3): [p.6]. Disponível em: http://www.scielo.br/pdf/jped/ v83n3/v83n3a06.pdf

Artigo apresentado em 14/3/2010

Aprovado em 10/7/2010

Versão final apresentada em 30/10/2010 